Trauma Surgery \& Acute Care Open

\title{
Intrahepatic vascular trauma
}

\author{
Melike Harfouche, David V Feliciano
}

Department of Surgery, $R$ Adams Cowley Shock Trauma Center, University of Maryland School of Medicine, Baltimore, Maryland, USA

Correspondence to Dr Melike Harfouche; melike. harfouche@gmail.com (c) Author(s) (or their employer(s)) 2021. Re-use permitted under CC BY-NC. No commercial re-use. See rights and permissions. Published by BMJ.

\section{To cite:}

Harfouche M, Feliciano DV.

Trauma Surg Acute Care Open 2021;6:e000675.

\section{HISTORY}

An 18-year-old man presented to the trauma center with four gunshot wounds to the following areas: left lower flank, left lower quadrant of the abdomen, left supraclavicular region and left scapula.

\section{EXAMINATION}

The patient was awake but alternated between periods of agitation and lethargy. He had a heart rate of 140 beats/min, a blood pressure of 100/60 $\mathrm{mmHg}$, a respiratory rate of 12 breaths/min, and appeared pale with cool and clammy skin. Breath sounds were clear bilaterally. His left supraclavicular wound did not exhibit any signs of overt bleeding, nor was there an expanding hematoma, and he had a palpable left radial pulse. His abdominal examination was significant for the gunshot wounds as described earlier and tenderness over the left flank.

\section{MANAGEMENT}

Large bore intravenous access was obtained, and transfusion with whole blood was initiated. A Focused Assessment for the Sonographic Evaluation of the Trauma Patient (FAST) documented a fluid stripe in the right hepatorenal fossa. A foreign body $\mathrm{X}$-ray series was then performed (figure 1). The patient was taken to the operating room where an emergency exploratory laparotomy was performed. A moderate amount of hemoperitoneum and bile staining was noted in the lesser sac.

The following injuries were noted: (1) anterior and posterior perforations of the stomach, (2) a through-and-through central injury to the left lobe of the liver, (3) a perforation of the right hemidiaphragm and (4) an injury to the edge of the inferior pole of the spleen. The right upper quadrant of the abdomen was packed with laparotomy pads, and this appeared to control the bleeding. The tip of the spleen was inspected again and found to be hemostatic. The gastric injuries were then oversewn with a 3-0 polydioxanone (PDS) suture. Because of a concern about the proximity of the perforation in the right hemidiaphragm to the pericardial sac, a transdiaphragmatic pericardial window was performed. Saline irrigation confirmed that no cardiac injury was present. After passing a suction device into the right pleural cavity to evacuate any blood, the perforation in the right hemidiaphragm was repaired with a $\# 1$ polypropylene suture. Attention was then directed to the hepatic injury, which had a small amount of venous bleeding coming from the perforation in segment IV, but no bleeding from the second perforation in segment VIII.

\section{QUESTION}

Based on the appearance of the hepatic injury described previously, your choice for management would be to

A. Insert perihepatic packing/perform postoperative hepatic arteriogram.

B. Perform a hepatotomy connecting the perforations.

C. Insert a balloon catheter into the missile track.

D. Perform superficial hemostasis and insert drains.

The finger fracture technique was used to inspect the inferior perforation in segment IV, and bleeding from a hepatic venous branch was controlled with ligation. The remainder of the track appeared hemostatic, and the abdomen was then irrigated with $4 \mathrm{~L}$ of warm saline. The hepatic injury was inspected again, and there was no bleeding. A fibrin sealant patch was placed over the exposed hepatic parenchyma at each end of the track of the missile. After two \#19 Blake drains were placed above and below the left lobe of the liver, the abdomen was closed with a continuous \#1 looped PDS suture. At the end of the operation, the patient had received four units of whole blood, with two administered intraoperatively, had normal vital signs and a blood lactate level of $3.2 \mathrm{mmol} / \mathrm{L}$. A postoperative chest $\mathrm{X}$-ray demonstrated a moderate-sized right pneumothorax, and a \#28 Fr thoracostomy tube was inserted.

Approximately 20 hours after operation, the patient had a sudden increase in bloody output from his Blake drains and developed worsening tachycardia.

\section{QUESTION}

Which of the following is the most appropriate next step in management?

1. CT angiography (CTA).

2. Observation with hemoglobin check every 6 hours.

3. Return to the operating room/balloon tamponade of the missile track.

4. Return to the operating room and insert perihepatic packing.

\section{MANAGEMENT}

As blood transfusions were administered, a CTA of the abdomen and pelvis was obtained. This documented an arterioportal venous fistula within the track of the hepatic gunshot wound and a moderate amount of hemoperitoneum (figure 2). The patient was taken to the hybrid operating room where he underwent coil embolization of the intrahepatic left hepatic artery (figure 3). Of interest, he was noted to have an accessory left hepatic artery arising from the left gastric artery and a replaced right hepatic 


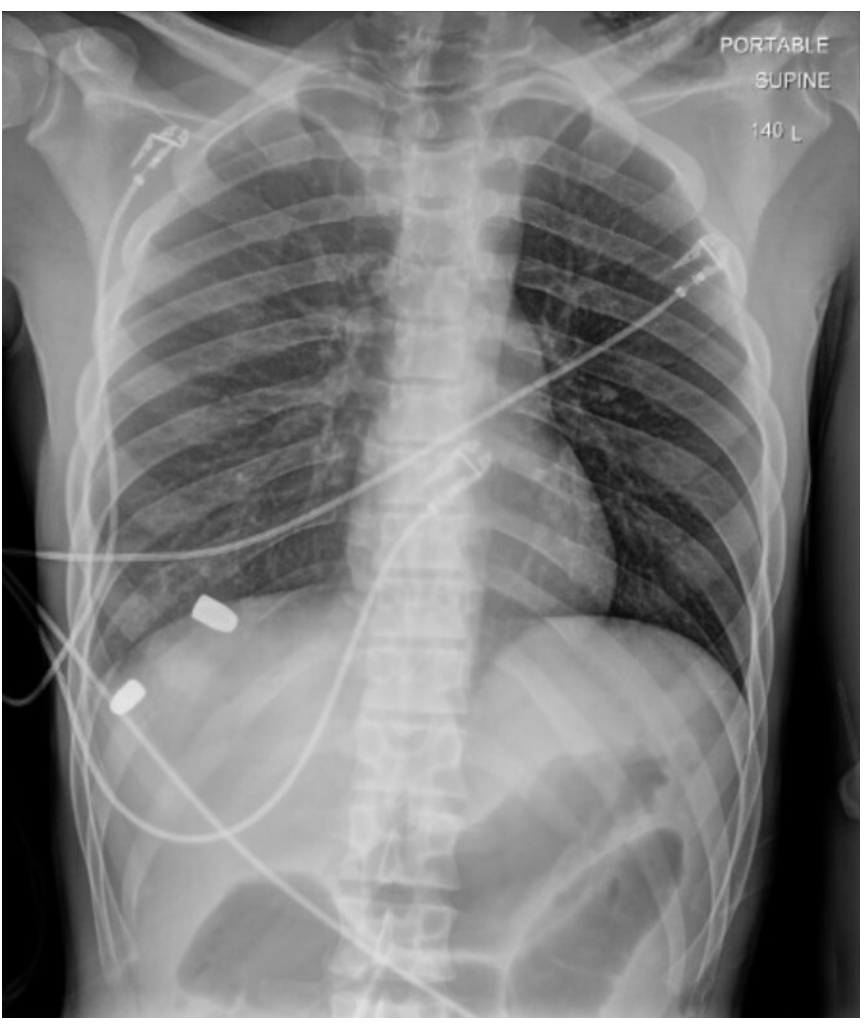

Figure 1 Foreign body series demonstrating retained bullets in the right upper quadrant.

artery arising from the superior mesenteric artery. A small amount of bleeding was noted from the inferior tip of the spleen on digital subtraction angiography. After this, he underwent a repeat laparotomy with evacuation of the hemoperitoneum, inspection of the liver (no further bleeding), splenectomy and closure of the midline incision.

After the second laparotomy, he had an uneventful recovery. A repeat CTA obtained on postoperative day 8 demonstrated a persistent $1.4 \mathrm{~cm}$ pseudoaneurysm within the left hepatic lobe. The abdominal drains were removed the same day, and he was discharged on hospital day 9. A subsequent CTA obtained 10 days later revealed that the pseudoaneurysm had decreased in size to $6 \mathrm{~mm}$.

\section{DISCUSSION}

There has never been a uniform consensus on the management of the patient with a gunshot or stab wound of the liver, presence of a moderate-sized or significant hemoperitoneum and no bleeding from the hepatic injury at laparotomy. Operative options for management include the following: (1) extensive

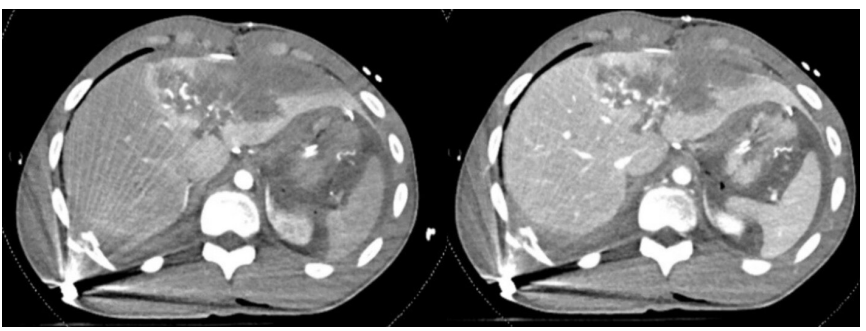

Figure 2 Arterial (left panel) and venous (right panel) phases of the CT arteriogram demonstrating arterioportal venous fistula and active bleeding in the gunshot track in the left hepatic lobe.
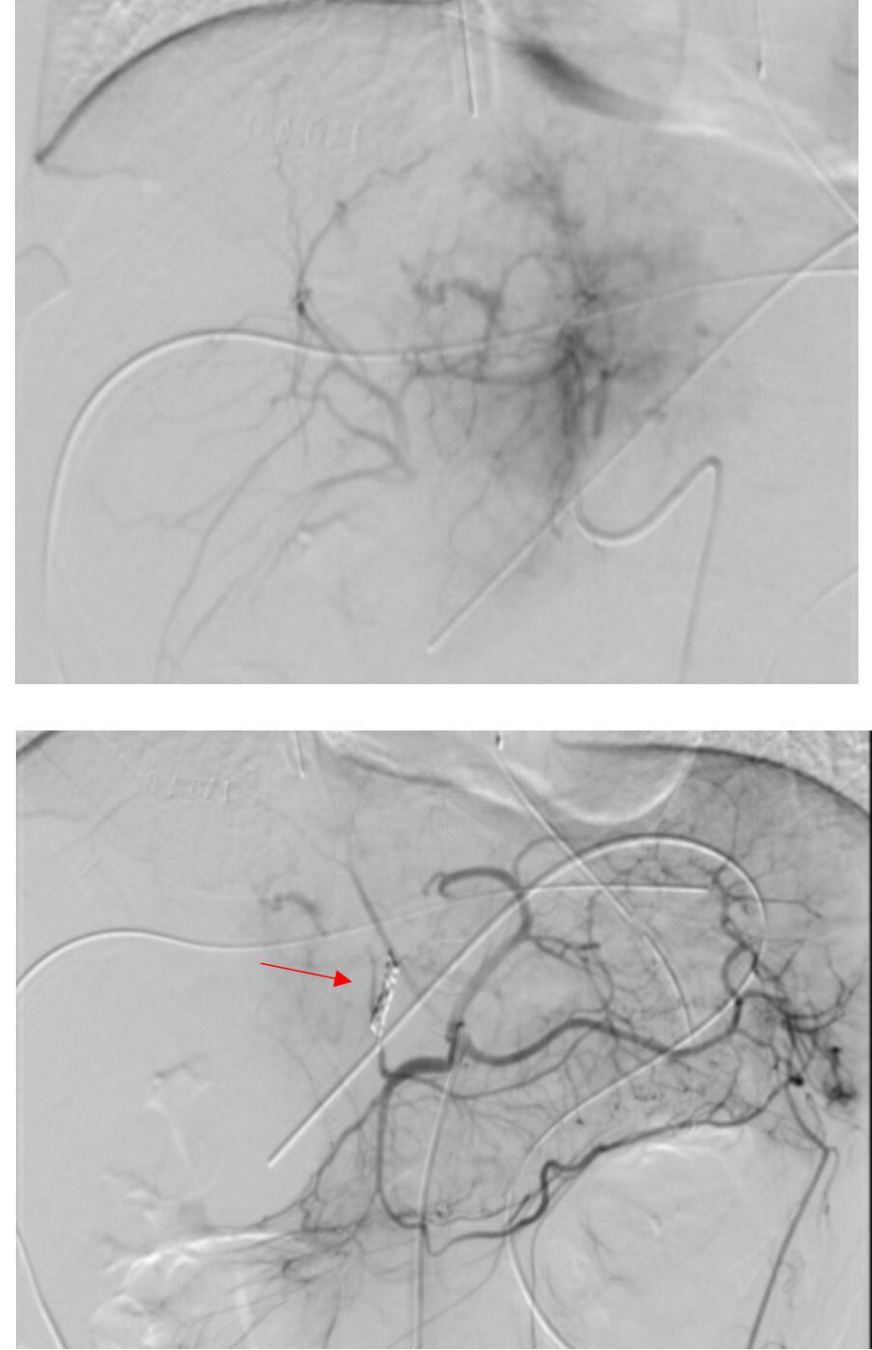

Figure 3 Top panel: hepatic arteriogram demonstrating active extravasation from the left hepatic artery. Lower panel: completion arteriogram from the celiac axis with coils in place (red arrow).

hepatotomy connecting entrance and exit sites of the missile, (2) insertion of an intrahepatic balloon for tamponade into the track of the missile, (3) insertion of perihepatic packing and hepatic arteriogram/possible angioembolization immediately after laparotomy; and (4) intraoperative hepatic arteriogram/possible angioembolization and/or intraoperative transinferior mesenteric venous embolization of a portal vein branch in a hybrid operating room. ${ }^{1}$

The first option of an extensive hepatotomy to expose an injured vessel that is not actively bleeding has always been unappealing. The second option of trying to pass a 'prophylactic' intrahepatic balloon is controversial, as well, as this may precipitate major hemorrhage. The technique of intrahepatic balloon tamponade to control ongoing hemorrhage was first described in the USA by William E Schroeder from Cook County Hospital in $1906^{2}$ and by multiple authors in the 1980s, 1990s and in 2011. ${ }^{3-6}$ The modern approach involves placing a 16 -inch $12-\mathrm{Fr}$ red Robinson catheter inside a 1 inch $\times 12$ inch Penrose drain and tying off each end of the Penrose drain down onto the Robinson catheter. This dual structure is gently guided into the missile track in the liver, and the Penrose drain is inflated with a $50 \% / 50 \%$ mixture of a radiographical contrast agent and normal saline until a tamponade effect is created. The addition of a 
contrast agent allows for assessment of adequate balloon inflation with X-rays as needed. The end of the Robinson catheter is passed through the abdominal wall, secured to the skin with a suture, and a Kelly clamp placed across it to maintain inflation of the balloon. A temporary abdominal closure is performed as the patient will be returned to the operating room in 48-72 hours. After deflation of the balloon, the device is removed and viable omental plugs are inserted into the missile track sites.

In the modern era, many experienced trauma surgeons would assume that there is an intrahepatic vascular injury that is no longer actively bleeding when a significant hemoperitoneum is present. Therefore, the third option of inserting perihepatic packing would be chosen. After a temporary closure or coverage of the abdomen, the patient is immediately transferred to an angiography suite for formal arteriography and possible angioembolization of a branch of the hepatic artery.

The fourth option mentioned previously is available only when there is a hybrid operating room and local endovascular expertise. After the introduction of a $5 \mathrm{Fr}$ sheath into the inferior mesenteric vein, a steerable catheter is passed through the splenic vein into the portal vein and a portal venogram is performed. As with arterial blushes, an intrahepatic venous blush is followed by venous embolization.

The patient described had a postoperative diagnosis of an intrahepatic arteriovenous fistula, a rare post-traumatic vascular lesion that can be caused by penetrating or blunt trauma. Newonset delayed hemorrhage from the liver and hemobilia are early symptoms of an arterioportal fistula, whereas symptoms days to months after injury are portal hypertension and esophageal varices. ${ }^{8}$ Patients with prior significant hepatic trauma who present with any of these symptoms should undergo further evaluation with hepatic arteriography and selective angioembolization. ${ }^{89}$

In recent years, there has been increased use of early postoperative contrast-enhanced CT or hepatic arteriography and then angioembolization as needed in patients with the American Association for the Surgery of Trauma (AAST) Organ Injury Scale (OIS) grade IV and $\mathrm{V}$ injuries or in those who undergo 'damage control' management of the injured liver. ${ }^{10-12}$ In the recent review of such patients from Los Angeles County Hospital/University of Southern California using preliminary CTA or direct hepatic arteriography, $8.1 \%$ of 'stable' patients had hepatic bleeding on the postoperative CT. In the group of 19 patients who went directly to hepatic arteriography, 57.9\% had 'active hepatic extravasation or pseudoaneurysm'. ${ }^{11}$

Another management issue in the patient described was the decision to perform a splenectomy for continuing hemorrhage from a minor splenic injury at the inferior pole at the second operation. Surgeons remember that the spleen receives $200 \mathrm{~mL}$ of blood flow/min. Therefore, capsular defects or perforations from missiles or knives should be oversewn and extensive loss of the capsule should be replaced with knitted absorbable mesh at the initial laparotomy, especially if a coagulopathy is present. Such simple techniques of 'splenorrhaphy', so common in the 1970 s and 1980s, have been forgotten by the current generation of trauma surgeons, fellows and surgical residents. The most common form of splenorrhaphy is with sutures with or without the application of a topical agent. ${ }^{13}$ After mobilization of the spleen, which often mandates ligation or clipping of the three most superior short gastric vessels, the location and OIS grade of the injury are confirmed. Continuous suture repair of a capsular defect or perforation is performed with a 00 or 000 chromic or polypropylene suture, often placed over a detached (dead) piece of greater omentum to compensate for capsular tearing as the suture is pulled tight.

Closing the capsule is usually sufficient to control hemorrhage. Of interest, in the four large reviews of splenorrhaphy (674 patients, most adults) published from 1988 to 90, the reoperation rate for bleeding after splenorrhapy ranged from $1.3 \%$ to $3.4 \% .{ }^{13-16}$ Although it is unlikely that the current generation of surgeons will duplicate the senior author's enthusiasm for splenorrhapy, the patient described would have undergone this approach in the past to preserve 'splenic immunity'.

Funding The authors have not declared a specific grant for this research from any funding agency in the public, commercial or not-for-profit sectors.

Competing interests None declared.

Patient consent for publication Not required.

Provenance and peer review Commissioned; internally peer reviewed.

Data availability statement There are no data in this work.

Open access This is an open access article distributed in accordance with the Creative Commons Attribution Non Commercial (CC BY-NC 4.0) license, which permits others to distribute, remix, adapt, build upon this work non-commercially, and license their derivative works on different terms, provided the original work is properly cited, appropriate credit is given, any changes made indicated, and the use is non-commercial. See: http://creativecommons.org/licenses/by-nc/4.0/.

\section{REFERENCES}

1 Belyayev L, Herrold JA, Ko A, Kundi R, DuBose JJ, Scalea TM, Morrison JJ. Endovascular adjuncts for hybrid liver surgery. J Trauma Acute Care Surg 2020;89:e51-4.

2 Schroeder WE. The progress of liver hemostasis - reports of cases (resection, sutures, etc). Surg Gynecol Obstet 1906;2:52-61.

3 Morimoto RY, Birolini D, Junqueira AR, Poggetti R, Horita LT. Balloon tamponade for transfixing lesions of the liver. Surg Gynecol Obstet 1987:164:87-8.

4 Poggetti RS, Moore EE, Moore FA, Mitchell MB, Read RA. Balloon tamponade for bilobar transfixing hepatic gunshot wounds. J Trauma 1992:33:694-7.

5 Demetriades D. Balloon tamponade for bleeding control in penetrating liver injuries. J Trauma 1998:44:538-9.

6 Ball CG, Wyrzykowski AD, Nicholas JM, Rozycki GS, Feliciano DV. A decade's experience with balloon catheter tamponade for the emergency control of hemorrhage. J Trauma 2011;70:330-3.

7 Stone HH, Lamb JM. Use of pedicled omentum as an autogenous pack for control of hemorrhage in major injuries of the liver. Surg Gynecol Obstet 1975;141:1038-4.

8 Feliciano DV, Pachter HL, Blumgart LH, Fong Y. Trauma to the liver vasculature, aneurysm and arteriovenous fistula. Surgery of the liver and biliary tract. 3rd edn. London: WB Saunders, 2000:1301-18.

9 Eastridge BJ, Minei JP. Intrahepatic arterioportal fistula after hepatic gunshot wound: a case report and review of the literature. J Trauma 1997;43:523-6.

10 Kutcher ME, Weis JJ, Siada DD, Kaups KL, Kozar RA, Wawrose RA, Summers JI, Eriksson EA, Leo SM, Carrick MM. The role of computed tomographic scan in ongoing triage of operative hepatic trauma: a Western trauma association multicenter retrospective study. J Trauma Acute Care Surg 2015:79:951-6.

11 Matsushima K, Hogen R, Piccinini A, Biswas S, Khor D, Delapena S, Strumwasser A, Inaba K, Demetriades D. Adjunctive use of hepatic angioembolization following hemorrhage control laparotomy. J Trauma Acute Care Surg 2020;88:636-43.

12 Kozar RA, Crandall M, Shanmuganathan K, Zarzaur BL, Coburn M, Cribari C, Kaups K, Schuster K, Tominaga GT. AAST patient assessment Committee. organ injury scaling 2018 update: spleen, liver, and kidney. J Trauma Acute Care Surg 2018;85:1119-22.

13 Feliciano DV, Sput-Patrinely V, Burch JM, Mattox KL, Bitondo CG. Cruse- Martocci P, Jordan GL Jr. Splenorrhaphy. the alternative. Ann Surg 1990:569-82.

14 Beal SL, Spisso JM. The risk of Splenorrhaphy. Arch Surg 1988;123:1158-63.

15 Pickhardt B, Moore EE, Moore FA, McCroskey BL, Moore GE. Operative splenic salvage in adults; a decade perspective. J Trauma 1989:10:1386-91.

16 Molin MR, Shackford SR. The management of splenic trauma in a trauma system. Arch Surg 1990;125:840-3. 